\title{
Solution structure and biophysical characterization of the multifaceted signalling effector protein growth arrest specific-1
}

\author{
Katja Rosti ${ }^{1}$, Adrian Goldman ${ }^{2,3}$ and Tommi Kajander ${ }^{1 *}$
}

\begin{abstract}
Background: The protein growth arrest specific-1 (GAS1) was discovered based on its ability to stop the cell cycle. During development it is involved in embryonic patterning, inhibits cell proliferation and mediates cell death, and has therefore been considered as a tumor suppressor. GAS1 is known to signal through two different cell membrane receptors: Rearranged during transformation (RET), and the sonic hedgehog receptor Patched-1. Sonic Hedgehog signalling is important in stem cell renewal and RET mediated signalling in neuronal survival. Disorders in both sonic hedgehog and RET signalling are connected to cancer progression. The neuroprotective effect of RET is controlled by glial cell-derived neurotrophic factor family ligands and glial cell-derived neurotrophic factor receptor alphas (GFRas). Human Growth arrest specific-1 is a distant homolog of the GFRas.

Results: We have produced and purified recombinant human GAS1 protein, and confirmed that GAS1 is a monomer in solution by static light scattering and small angle X-ray scattering analysis. The low resolution solution structure reveals that GAS1 is more elongated and flexible than the GFRas, and the homology modelling of the individual domains show that they differ from GFRas by lacking the amino acids for neurotrophic factor binding. In addition, GAS1 has an extended loop in the $\mathrm{N}$-terminal domain that is conserved in vertebrates after the divergence of fishes and amphibians.

Conclusions: We conclude that GAS1 most likely differs from GFRas functionally, based on comparative structural analysis, while it is able to bind the extracellular part of RET in a neurotrophic factor independent manner, although with low affinity in solution. Our structural characterization indicates that GAS1 differs from GFRa's significantly also in its conformation, which probably reflects the functional differences between GAS1 and the GFRas.
\end{abstract}

Keywords: GAS1, Growth arrest specific-1, Solution X-ray scattering, Protein structure, RET, Sonic hedgehog

\section{Background}

Growth Arrest Specific-1 gene (GAS1) was found in a screen to identify genes specifically expressed in growtharrested mouse cells [1]. The full-length cDNA of human GAS1 was cloned $[2,3]$ and the mature protein was found to contain 345 amino acids, a potential signal peptide, one $\mathrm{N}$-glycosylation site at Asn117 and an aminated Ser318 [2,3]. The aminated Ser318 allows the mature protein to be glycophosphatidylinositol (GPI) anchored to the cell membrane $[2,4]$.

\footnotetext{
* Correspondence: tommi.kajander@helsinki.fi

${ }^{1}$ Institute of Biotechnology, Structural Biology and Biophysics, University of Helsinki, Helsinki, Finland

Full list of author information is available at the end of the article
}

GAS1 was found to arrest cell cycle by stopping the cells in synthesis (S) phase $[1,5]$ and due to its ability to arrest cell proliferation in p53-dependent manner it has been considered to be a tumour suppressor protein [6,7]. Generally GAS1 might act as a tumour suppressor in adult brain, though the expression in brain leading to apoptosis has not been observed in adults [3,8]. Sequence comparison of human and murine GAS1 genes suggested that it has a conserved RGD-peptide sequence for possible RGD-dependent integrin binding at residues 306-308 [3].

Additionally GAS1 has been shown to have a significant role in development [9]. At early developmental stages GAS1 is expressed in most embryonic tissues. During development GAS1 has been reported to inhibit 
cell proliferation and to mediate cell death, to be involved in embryonic patterning, and to support growth of the cerebellum $[3,8]$.

GAS1 is clearly a multifunctional protein, since it signals through at least two different kinds of transmembrane receptor proteins, Rearranged during transformation (RET) [8] and the Hedgehog receptor protein patched-1 [10,11]. The Hedgehog signalling pathway is important in development, stem cell renewal, and cancer progression. GAS1 is able to bind sonic hedgehog $(\mathrm{SHH})$ and activate the signalling pathway from patched-1 $[10,11]$. RET, on the other hand, is a transmembrane kinase, first identified as a proto-oncogene [12]. Overactivity of RET can cause several types of cancers, and loss-of-function mutations cause varying degrees of loss in the enteric nervous system resulting in Hirschprung's disease (see e.g. Robertson and Mason [13]). Normally RET mediated signalling is controlled by Glial cell-derived neurotrophic factor family ligands (GFLs) and Glial cell-derived neurotrophic factor receptor alphas (GFR $\alpha$ ), which form a four-member protein family (GFR $\alpha 1-4)$ [14].

Of these, GAS1 has highest (28\%) similarity to GFR $\alpha 1$, while GAS1 and GFR $\alpha 4$ both have only two domains unlike GFR $\alpha 1-3$, which consists of three domains [15]. The secondary structure of mammalian GAS1 is predicted to be mostly $\alpha$-helical separated by short $\beta$-strands and to have a long unstructured C-terminal domain [15]. By binding GFLs, GFR $\alpha$ s take part in controlling the survival of neurons, neuron branching, and functional recovery [14]. The most studied member of GFLs is GDNF, which was identified due to its function as a survival factor for midbrain dopaminergic neurons [14]. GDNF forms a complex with GFR $\alpha 1$ and promotes the survival of neurons [16]. GFLs, in general, are dimeric proteins and they are capable of binding two GFR $\alpha$ receptors per ligand [14]. After the formation of GFR $\alpha$-GFL complex, the complex then binds to the transmembrane tyrosine kinase RET [16].
Despite the structural similarity to GFRas, GAS1 differs from them functionally because it is able to bind to RET in a ligand independent way [8]. In addition, the intracellular signalling pathway is most probably different than for GFR $\alpha$-GDNF complex, and GAS1 bound to RET blocks AKT activation, and increases ERK activation [8].

GAS1 has been suspected to be an ancestor of GFR $\alpha$ proteins $[8,15,17]$. Thus the four GFLs and GFR $\alpha$ s could have been generated by genome duplications at the origin of vertebrates, and at this point the gene encoding GAS1 could have diverged from GFR $\alpha$-like proteins $[17,18]$.

It has been hypothesised that the relative abundance and localization of GFR $\alpha$ s, GFLs and GAS1 could determine in certain conditions whether cells survive or die [15]. Furthermore, GAS1 expression is increased in neuronal cell death during early development [19]. Therefore, GAS1 could work as a switch between proliferation and differentiation in neuronal development [8]. GAS1 has been shown to colocalize to lipid rafts with RET [8]. This has led to the hypothesis that GAS1 could be a negative modulator of GDNF signalling and able to control GDNF stimulation via RET $[8,20]$.

\section{Results}

Production and purification of human GAS1 protein

After cloning and expressing human GAS1 in Tricoplusia $\mathrm{Ni}$ cells, we purified secreted GAS1 from the insect cell growth medium using Ni-affinity chromatography (Figure 1), and the identity and size of the expressed protein was verified with a western blot (Figure 1). The purified protein is glycosylated and therefore does not run exactly according to excepted molecular weight on the SDS-PAGE, but slightly higher. Thrombin was used to cleave off the tags, and the size of the protein after cleavage was verified by SDS-PAGE and MALDI-TOF

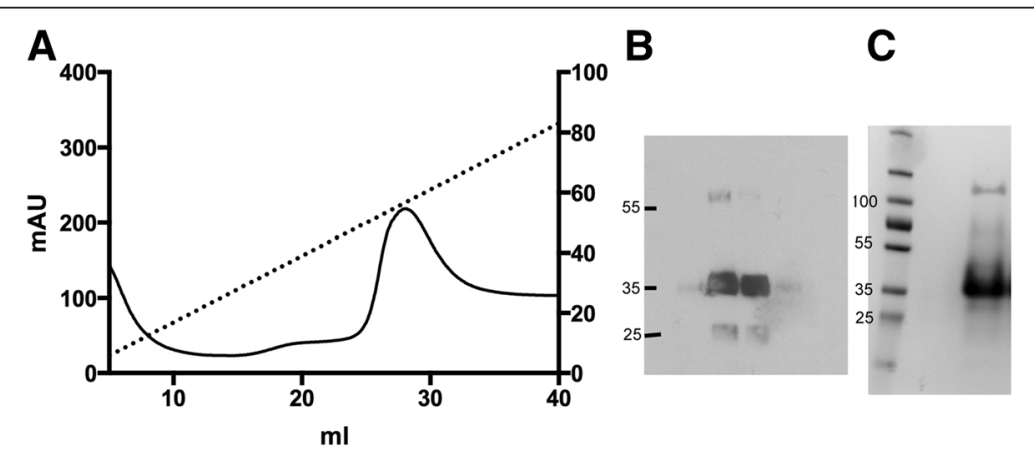

Figure 1 Purification of recombinant GAS1 from insect cells. A) Ni-affinity chromatogram for GAS1 purification B) Western blot of fractions from the Ni-affinity chromatography peak at ca. $28 \mathrm{ml}$. Fractions of $1 \mathrm{ml}$ were collected, and fractions from peak area at 23, 27, 29 and 33 ml were tested in the western blot. C) SDS-PAGE analysis of GAS1 purification (left lane, molecular weight marker, with sizes indicated; right lane, purified GAS1 after gel filtration; the gel was Coomassie stained.). 
mass spectroscopy. The yield of purified protein was on average ca. $1 \mathrm{mg} / \mathrm{L}$.

Based on the primary sequence one $\mathrm{N}$-glycosylation site was predicted at Asn117 located in the $\mathrm{N}$-terminal domain. The corresponding site in the GFR $\alpha$-structures is located at the domain interface between the two homologous disulphide rich domains, in a tightly packed two-domain structure [21,22], suggesting that the GAS1 overall conformation is quite likely very different (see below, Figure 2).

When the protein was treated with PNGase F to remove glycans, the size of the protein diminished slightly on SDSPAGE (data not shown), and based on MALDI-TOF analysis, we observe a decrease in molecular weight of $c a$.
$900 \mathrm{Da}$; the glycosylated protein had a molecular mass of $29.8 \mathrm{kDa}$ and the de-glycosylated protein of $28.9 \mathrm{kDa}$, according to MALDI-TOF, while the theoretical molecular mass of the protein without glycosylation is $29.0 \mathrm{kD}$, thus matching well with the mass spectrometry results. The result obtained for glycosylated protein corresponds to approximately one $\mathrm{N}$-glycan added post-translationally in the insect cells. The purified protein was functional in binding to RET in vitro, and found to be over $90 \%$ pure on SDSPAGE, and monodisperse in solution after gel filtration.

\section{GAS1 is a monomer is solution and highly thermostable}

The cleaved, non-tagged protein was found to be a monomer by analytical size exclusion chromatography and

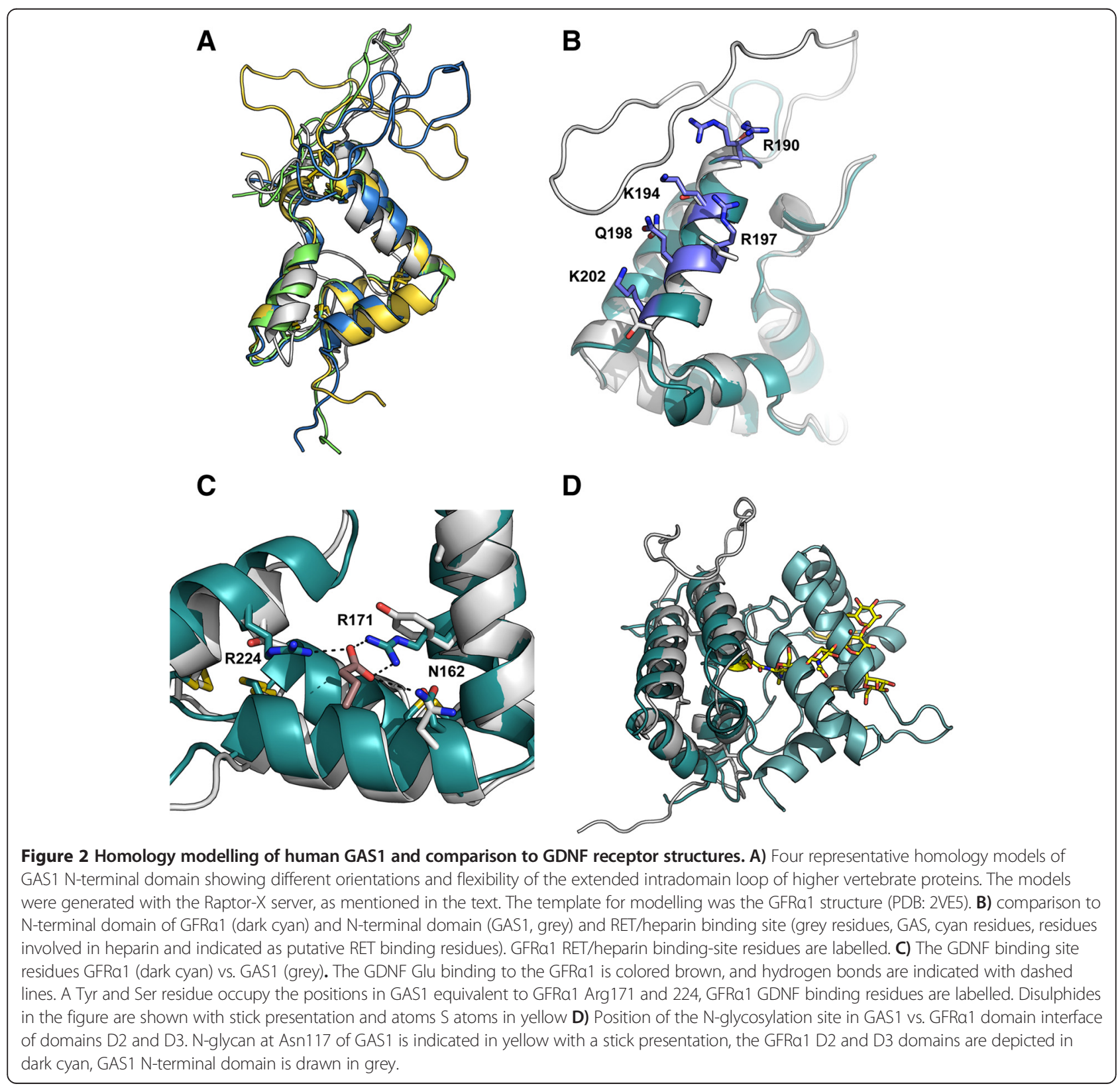


multi-angle light scattering (SEC-MALLS) (Figure 3). At $1 \mathrm{mg} / \mathrm{ml}$ and $4.5 \mathrm{mg} / \mathrm{ml}$ the SEC-MALLS runs gave a single peak with molecular mass of $c a .31-33 \mathrm{kDa}$ (Figure 3), matching quite well to the theoretical size of monomeric GAS1 $(29.0 \mathrm{kDa})$ considering the additional glycosylation at one site. Similarly, based on the small-angle X-ray scattering (SAXS) data, the molecular weight matches most closely to a monomer (Table 1). In our opinion, this is likely to reflect the oligomerization state of the lipidanchored protein, which is unlikely to be affected by the anchor. No detectable oligomerization was observed in native PAGE or gel filtration at $4.5 \mathrm{mg} / \mathrm{ml}$, while in SAXS

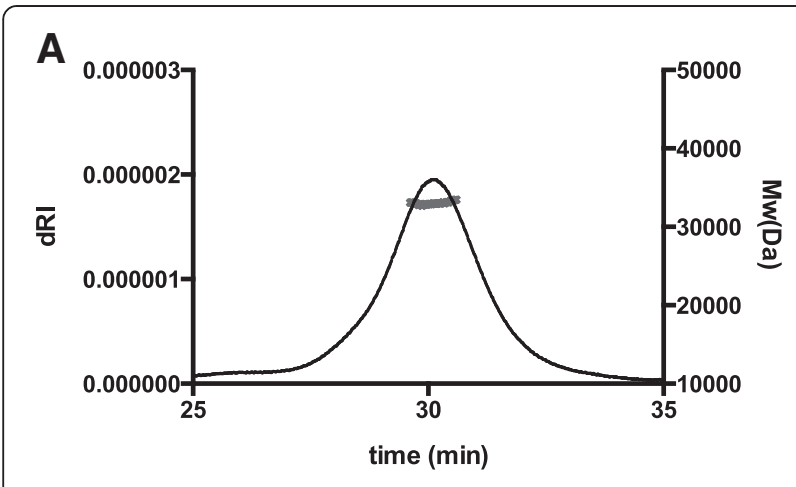

B

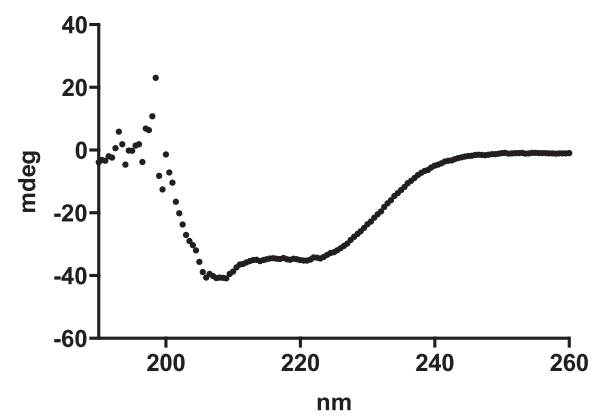

C

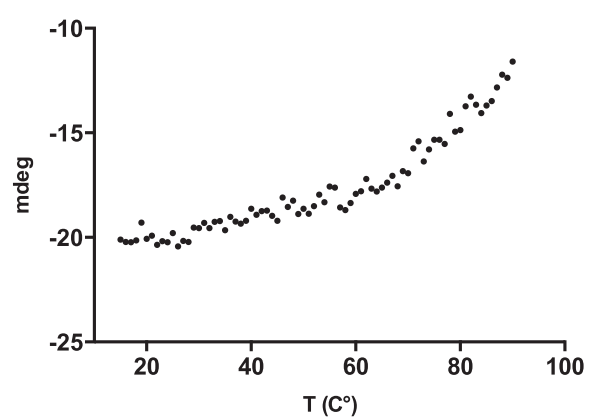

Figure 3 GAS1 analytical gel filtration, circular dichroism and thermal unfolding. A) GAS1 sample was run on Superdex 200 10/300 gel filtration column in TBS at $0.5 \mathrm{ml} / \mathrm{min}$, at protein concentration of $1 \mathrm{mg} / \mathrm{ml}$. A single major peak at $30 \mathrm{~min}$ (X-axis) eluted and based on multi-angle light scattering had molecular weight (right $Y$-axis) of $c a$. $33 \mathrm{kDa}$, matching relatively well with theoretical molecular weight of the monomer. The peak is plotted as a function of $\mathrm{dRI}$ signal (left Y-axis). B) The CD spectrum of GAS1 and $\mathbf{C}$ ) the residual thermal denaturation of GAS1 as monitored by CD at $222 \mathrm{~nm}$.
Table 1 SAXS-derived size parameters for GAS1

\begin{tabular}{ll}
\hline I(0) (Guinier) & 25.08 \\
$I(0)$ (Porod) & 24.8 \\
$D_{\max }(\mathrm{nm})$ & 10.5 \\
$\mathrm{R}_{\mathrm{g}}($ Guinier $/ \mathrm{nm})$ & 3.01 \\
$\mathrm{R}_{\mathrm{g}}($ Porod $/ \mathrm{nm})$ & 3.00 \\
Porod volume $\left(\mathrm{V}_{\mathrm{p}}\right)$ & 54.2 \\
$\mathrm{M}_{\mathrm{w}}($ theoretical) & $29158.3 \mathrm{~g} / \mathrm{mol}$ \\
$\mathrm{M}_{\mathrm{w}}($ calc) (Guinier) & $25.1 \mathrm{kDa}$ \\
$\mathrm{M}_{\mathrm{w}}($ calc) (Porod vol.) & $31.9 \mathrm{kDa}\left(\mathrm{V}_{\mathrm{p}} / 1.7\right)$ \\
\hline
\end{tabular}

The Guinier I(0)-value was calculated against an absolute reference (scattering of water relative to sample) [23] and the I(0) for the sample is then equal to the molecular weight. Molecular weight from the Porod volume is estimated according to Petoukhov et al. [24].

data an effect from residual aggregation was evident at higher concentrations.

Circular dichroism (CD) spectroscopy was used to verify the secondary structure content of GAS1 and, as expected, the CD spectrum was typical for an $\alpha$-helical protein (Figure 3). A measured temperature denaturation curve with $\mathrm{CD}$ gave a result with partial melting of the structure when heated to $90^{\circ} \mathrm{C}$ (Figure 3). However, full temperature denaturation was not possible to obtain by $C D$, nor by differential scanning calorimetry (data not shown), possibly due to the high disulphide content of the protein. This suggests that the domain structure is thermally very stable. The decrease in $C D$ signal at $222 \mathrm{~nm}$ did not even reach the midpoint of denaturation when heated to $90^{\circ} \mathrm{C}$ (Figure 3).

\section{Sequence analysis and evolution of GAS1}

The GAS1 protein domain structure is defined by two GFR $\alpha$-like domains, with 10 conserved disulphide bridgeforming cysteines in each domain [25]. GAS1 is present in all the vertebrates, and homologs are also found in lower chordates (e.g. Ciona and Amphioxus [17]). In addition, GAS1 homologs also occur in C. elegans and honeybee, but not, surprisingly, in Drosophila. The sequence identity to vertebrate proteins, however, is quite low: $c a .21-24 \%$ for honeybee and only $14-19 \%$ for the worm sequence (Table 2). Two conserved cysteines are missing from the C. elegans sequence (Figure 4), and thus the protein fold might not be fully conserved in the C. elegans homolog (phas-1) [26]. Alignment of the GAS1 sequences shows that, in higher vertebrates, the N-terminal domain has an insertion with low sequence complexity (Figure 4), apparently forming an extended loop structure (Figure 2). Mammals have also an RGD sequence in the C-terminal linker region. Also, a single $\mathrm{N}$-glycosylation site at Asn117 is predicted to be conserved based on sequence in all vertebrates, while it is not present in the invertebrates. In the set of conserved residues beyond the structural cysteines 
Table 2 Amino acid sequence identities (\%) within the GAS1 protein family

\begin{tabular}{|c|c|c|c|c|c|c|c|c|c|c|c|c|c|}
\hline & Human & $\begin{array}{l}\text { Sus } \\
\text { scrofa }\end{array}$ & $\begin{array}{l}\text { Bos } \\
\text { Taurus }\end{array}$ & $\begin{array}{l}\text { Canis } \\
\text { Lupus }\end{array}$ & Mouse & $\begin{array}{l}\text { Gallus } \\
\text { gallus }\end{array}$ & Alligator & Anolis & Xenopus & Latimeria & $\begin{array}{l}\text { Danio } \\
\text { rerio }\end{array}$ & Apis & C. elegans \\
\hline Human & 100 & & & & & & & & & & & & \\
\hline Sus scrofa & 95.3 & 100 & & & & & & & & & & & \\
\hline Bos Taurus & 94.1 & 94.4 & 100 & & & & & & & & & & \\
\hline Canis Lupus & 91.1 & 91.4 & 90.2 & 100 & & & & & & & & & \\
\hline Mouse & 85.4 & 85.4 & 84.9 & 82.9 & 100 & & & & & & & & \\
\hline Gallus gallus & 61.9 & 61.7 & 60.1 & 62.1 & 59.6 & 100 & & & & & & & \\
\hline Alligator & 60.3 & 60.7 & 59.9 & 59.9 & 60.1 & 70.9 & 100 & & & & & & \\
\hline Anolis & 55.8 & 56.2 & 54.5 & 57 & 55.7 & 54.7 & 57.6 & 100 & & & & & \\
\hline Xenopus & 51.2 & 51.7 & 50.8 & 50.6 & 50.5 & 52.2 & 55 & 48.4 & 100 & & & & \\
\hline Latimeria & 47.2 & 47.4 & 46.6 & 46.3 & 45.9 & 48.4 & 50.5 & 42.1 & 49 & 100 & & & \\
\hline Danio rerio & 35.2 & 34.5 & 35 & 35.6 & 35.8 & 37 & 38.7 & 34.2 & 37.6 & 43.4 & 100 & & \\
\hline Apis & 22.1 & 21.7 & 21.3 & 21.6 & 21.1 & 23.1 & 23.7 & 22.6 & 22.1 & 22.8 & 23.7 & 100 & \\
\hline C.elegans & 15.6 & 15.6 & 14.6 & 15.5 & 14.3 & 14.7 & 15.9 & 14.2 & 19 & 17.8 & 17.1 & 15.4 & 100 \\
\hline
\end{tabular}

Pairwise identities between species that are over $70 \%$ are shown in bold.

(or positions with highly conserved mutations e.g. Asp to Glu) (Figure 4) a subset are present only in the vertebrate proteins, and, other than the conserved cysteines, only ten residues are conserved also in C. elegans.

When the conserved amino acid residues are displayed onto the surface of the modelled domains, the most conserved surface patch is found on the $\mathrm{N}$-terminal domain surface formed by residues on helices 3-5, whereas the C-terminal domain surface did not reveal large patches of conservation (Figure 4). Here conservation is defined by $>75 \%$ sequence similarity amongst the residue groups KHR, ED, NQSTGP, ILMVCA and FYW.

\section{Homology modelling of GAS1 domains and comparison to GFRas}

We constructed homology models of both GAS1 domains with the RaptorX-server (http://raptorx.uchicago. edu/) [27], designed for low sequence homology-based modelling. The models for both domains fit well to the GFR $\alpha$-structure (PDB: 2VE5) [22]. As described above, the N-terminal domain of mammalian GAS1-proteins contain a large inserted loop with low sequence complexity, which based on modelling indeed appears to form a large flexible loop, but whether this region has functional significance or not remains unclear.

Modelling of GAS1 has partially been done before also by Cabrera et al. [8] and Schueler-Furman et al. [15]. Here our aim was to study possible conservation of the ligand binding regions of GFR $\alpha$ s vs. GAS1, to do more detailed analysis on the structure, and to provide models for the analysis of SAXS data (see below).

Although the sequence identity to the related GFR $\alpha$ structures is low, the cysteines involved in disulphide bridges are well conserved for the two GFR $\alpha$-type domains and make structure prediction possible. The Nterminal domain of GAS1 is equivalent of the second domain in GFR $\alpha$ s, which contains the growth factor binding site. We aligned our model of GAS1 with the GFR $\alpha 1: G D N F$ complex structure [22], and, based on the structural alignment, the binding region for the GDNF is not conserved in GAS1 (Figure 2). Similarly the conserved binding residues in GFR $\alpha 2$ :Artemin complex (PDB: 2GH0) [21], are not present in GAS1. In fact, the key ionic residues required for ligand binding are conserved in both these structure, but not present in GAS1. The conserved key residues for GDNF binding in GFR $\alpha 1$ are Arg171, Arg224 and Asn162. In our structural analysis GAS1 has Tyr26, Thr100, Gln17 in equivalent side chain positions; in GAS1, the ion triplet required for growth factor binding [22] is absent.

It has also been suggested by Wang et al. [21] and Parkash et al. [22] that a RET binding region would be located mostly in the second ("D2") domain on the GFR $\alpha$ s and would involve the GFR $\alpha 1$ residues Arg190, Lys194, Arg197, Gln198, Lys202, Arg257, Arg259, Glu323, and Asp324. This site forms a highly positively charged patch on the surface of GFR $\alpha 1$, identified also as a heparin binding site by Parkash et al. [22]. We analysed the equivalent region in the $\mathrm{N}$-terminal domain of GAS1, but found no conservation between the GFR $\alpha 1$ structure and GAS1 (Figure 2). Overall GAS1 is not positively charged, as would be expected of a typical heparin-binding molecule. The calculated pI-value for human GAS1 is 5.0 whereas for human GFR $\alpha$ s the values range from 7.5-7.6 $(\mathrm{GFR} \alpha 2-3)$ to 8.4 (GFR $\alpha 1)$ and 10.1 (GFR $\alpha 4)$. Also, GAS1 does not contain a highly positively charged patch in the suggested RET/heparin binding region, and heparin affinity chromatography of GAS1 showed no significant binding to 


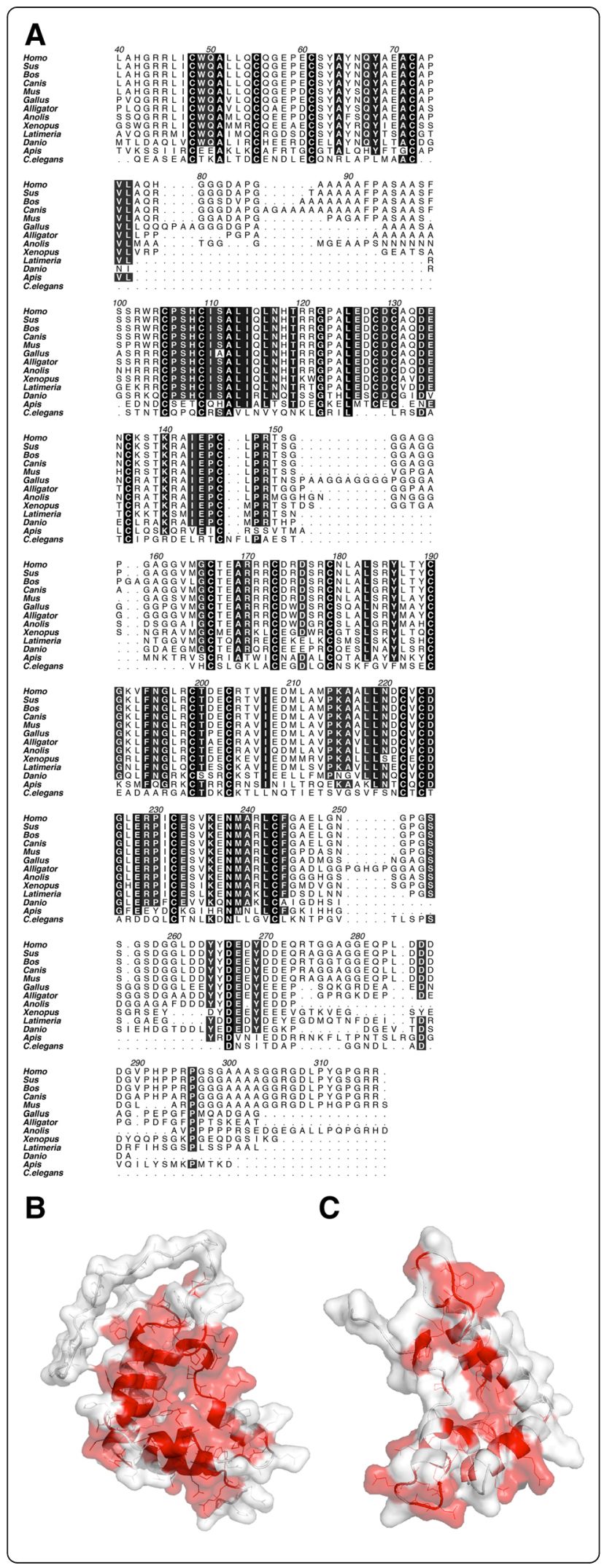

Figure 4 The GAS1 family sequence alignment. A) The sequences start from the beginning of the mature human GAS1 and numbered according to the human amino acid numbering. Residues over ca. $85 \%$ conserved (11/13) are coloured with a black-to-grey scale, in higher vertebrates (mammals) there is an extended loop in the $\mathrm{N}$ terminal domain around residues 80-100 (human GAS1 numbering). The C-termini are poorly conserved (residues beyond 250), note the RGD sequence at 306-308. B) Conserved surface features on GAS1 displayed on the $\mathrm{N}$-terminal domain. C) Conserved surface features on GAS1 displayed on the C-terminal domain; conserved sites in B and C are coloured in red (with $>75 \%$ sequence similarity, see text).

the column (Figure 5), whereas the well-known heparin binding protein HBGAM eluted only at $1 \mathrm{M} \mathrm{NaCl}$ (Figure 5). Finally, modelling of GAS1 N- terminal domain shows that glycosylated Asn117 will be situated at the position equivalent to the domain interface between domains D2 and D3 in the GFR $\alpha$ structures (Figure 2).

\section{Structural characterization of GAS-1 by solution X-ray scattering}

Solution X-ray scattering (SAXS) data indicated that GAS1 is monomeric at $0.8 \mathrm{mg} / \mathrm{ml}$ in solution based on the Porod volume and Guinier plots (Table 1): at higher concentrations the protein starts to aggregate, and the data beyond $1 \mathrm{mg} / \mathrm{ml}$ could not be analysed. Rigid body modelling of the structure was done based on homology models of the individual domains, and elongated models gave the best fits (Figure 6). We also calculated ab initio envelopes, which matched well with rigid body modelling of the structure (Figure 6). Both differ significantly from the compact GDNF co-receptor structures [21,22]. However, as it is clear that the structure is likely to be flexible, in particular the C-terminal long unstructured region, we also did ensemble fitting of the model against the data. This resulted in a bimodal ensemble represented by four major structures selected from the initial random pool of 10000 structures, which fit to the data with $X^{2}=0.84$ (Figure 6). The selected structures represent states with extended and collapsed C-terminal linkers and variable orientations of the domains relative to each other (Figure 6). Taken together it appears from the SAXS data that the orientation of the domains of GAS1 relative to each other is not fixed; clearly the protein exists in two populations of extended and collapsed conformations.

\section{Binding and affinity of GAS1 to RET in vitro}

We tested whether GAS1 is able to directly interact with RET in a ligand independent way, as previously reported [8]. For this purpose, and to determine the affinity of the interaction, the RET receptor was coupled to a chip for surface plasmon resonance assay, and binding of a concentration series of GAS1 to immobilized RET was measured. A $K_{\mathrm{d}}$-value of $12.2 \pm 8.2 \mu \mathrm{M}$ was measured for the 

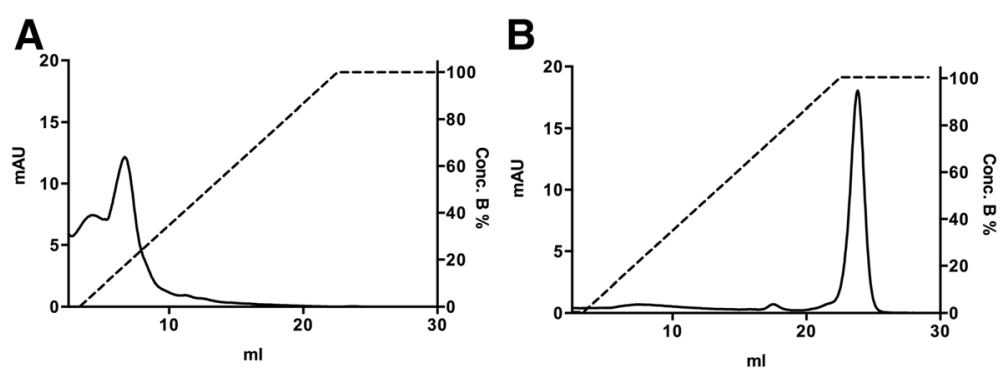

Figure 5 Heparin affinity chromatography of GAS1. A) Elution of GAS1 as a function of salt concentration. B) Elution of HBGAM as a function of salt concentration. Chromatograms are plotted with absorbance in mAU unit (right y-axis) and salt concentration gradient to $1 \mathrm{M} \mathrm{NaCl}(\%)$ (left y-axis), against volume in $\mathrm{ml}$.

interaction in vitro (Figure 7). The kinetics of the interaction were too fast to allow for measurement of onand off-rates, as is evident from the time scale of the binding and dissociation from the sensograms (Figure 7).

\section{Discussion}

We have overexpressed and purified the human GAS1 protein in soluble form without the GPI-anchor, and biophysically characterized the protein. We constructed homology models for both domains of GAS1 and were able to analyse the domain structure of the protein in comparison to the structurally related GFR $\alpha$ s. As reported earlier by others [8], GAS1 has clearly two GFR $\alpha$-like domains, but we have shown here that GAS1 differs significantly from GFR $\alpha$ s in both sequence and in structure.

The differences can be characterized as follows: Firstly, GAS1 has a large, 10-15 amino acid unstructured, low complexity Ala/Gly/Pro-containing loop in the $\mathrm{N}$ terminal domain. This loop region is present in higher vertebrates, in mammalians and chicken, but not in fish (Figure 4). Whether this loop might have some function remains unknown. Secondly, the two-domain structure of GAS1 appears to be more flexible overall than in the characterized GFR $\alpha$ structures. In the GFR $\alpha$ s, the functional domains D2 and D3 form a compact structure, whereas GAS1 SAXS analysis reveals a flexible ensemble of structures, with the $\mathrm{N}$ - and $\mathrm{C}$-terminal domains as independent structural units. This might reflect the location of the functional binding regions of the molecule versus those of the GFR $\alpha$ s. As expected, the protein is $\alpha-$ helical based on the CD spectrum. It is somewhat intriguing that we were not able to fully denature the protein; apparently the disulphide-linked arrangement of the domains is highly thermostable, and this might be a general feature of the GFR $\alpha$-family.

The structural flexibility is probably a conserved feature in the protein family, as the single $\mathrm{N}$-glycosylation site in the human protein is conserved in chordates. This $\mathrm{N}$-glycan blocks the GFR $\alpha$-equivalent domain interface, and hence the formation of that type of compact structure. It has been also observed that this glycosylation site might have functional significance for SHH binding [28].

Our sequence analysis and that by Hätinen et al. [17] suggest that GAS1 is conserved during evolution, with homologs in chordates (from Ciona and Amphioxus), arthropods and roundworms, thus possibly representing an ancestral GFR $\alpha$-like protein [17] However, the sequence identity from chordate to invertebrates (e.g. honey bee and C. elegans) genes is low, 14-19\% for the worm phas-1 homolog of GAS1 [26], and it remains an open question whether the insect or worm genes identified as GAS1 actually share any of the functions of vertebrate GAS1/GFR $\alpha$ type of receptors, either in RET or the hedgehog signalling.

GAS1, as well as GFR $\alpha$-like proteins, are conserved beyond vertebrates, while GFLs are not expressed in non-vertebrates. This suggests that either RET binding, independent of GFLs is conserved, or that there are alternative receptors for GAS1. In case of GAS1, this could be $\mathrm{SHH}$ and patched-1. Interestingly in Drosophila, the GRF $\alpha$-like protein does not interact with RET but does interact with Drosophila NCAM analog, FasII [29]. The mammalian GFLs are known to be ligands of NCAM [30]: whether GAS1 might interact with NCAM homologs remains to be investigated.

When we compared our model with the GFR $\alpha 1$ structure it was clear that the crucial amino acids for GFL binding are not conserved in GAS1, and it most likely lacks the ability to bind GFL-like ligands, as they all share the same binding mode [21,22]. Indeed Cabrera et al. [8] reported that GAS1 is not able to bind GDNF. While GAS1 lacks the ability to bind GFL-type of ligands, our in vitro binding data support the findings by Cabrera et al. [8] that GAS1 can bind RET in a ligand independent manner, and possibly alter the intracellular signalling of RET.

The affinity of GAS1 for RET is significantly lower than that of the GFR $\alpha$-GDNF ligand complex in solution $\left(K_{\mathrm{d}}=12.2 \mu \mathrm{M}\right.$ versus $0.2 \mathrm{nM}$ for GFR $\alpha 1-\mathrm{GDNF}$ binding 


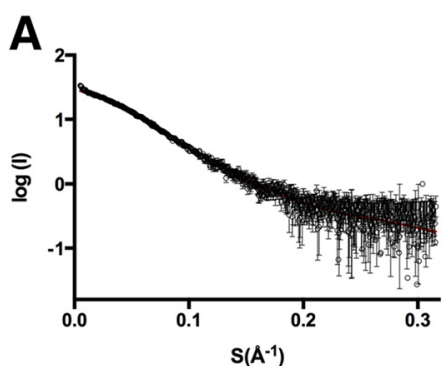

C

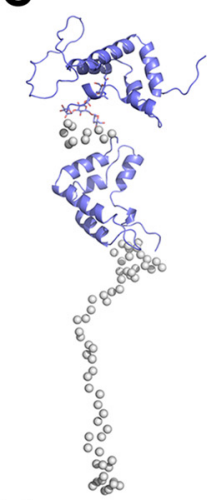

$\mathbf{E}$

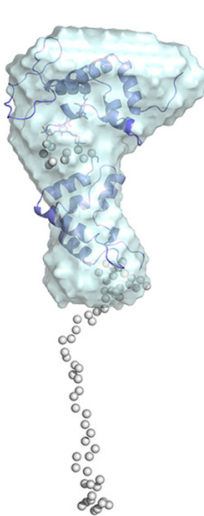

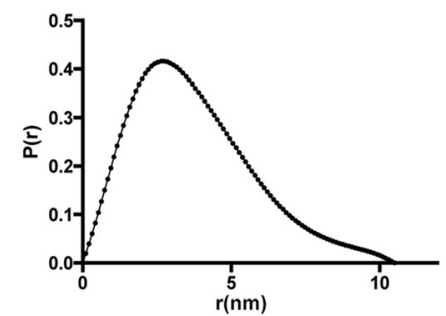

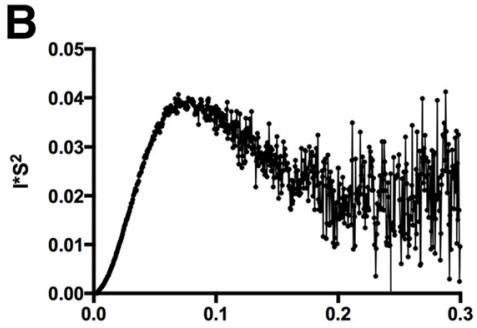

D
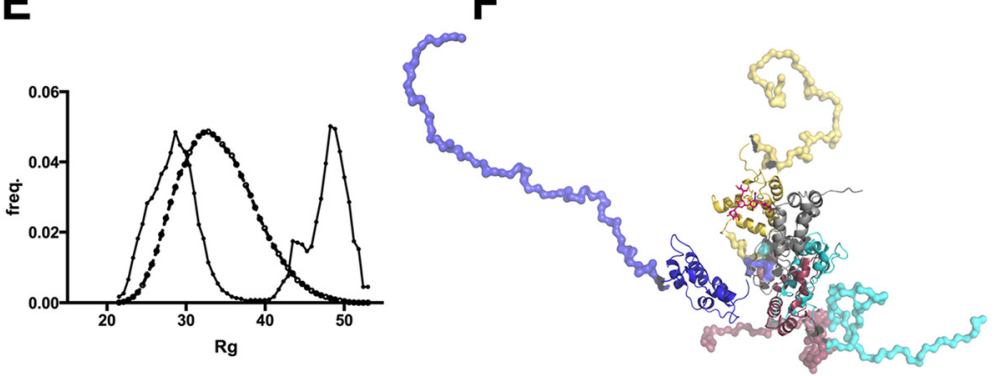

Figure 6 Rigid body and ab initio modelling of GAS1 based on SAXS data. A) Scattering curve and fit of CORAL rigid body model (red line) to observed data. B) The Kratky-plot from the experimental data, suggesting a folded structure with some flexibility. C) CORAL generated model with $\mathrm{N}$ - and C-terminal domains as rigid bodies (blue) with flexible linker regions (grey beads; left), and the ab initio model for GAS1 generated by DAMMIN (green; average of 10 calculations) fitted over the rigid body model (right). D) The distance distribution calculated for GAS1 SAXS data. E) SAXS ensemble modelling of GAS1 solution conformations shown as the statistical distribution of $\mathrm{R}_{\mathrm{g}}$-values of best fitted models (continuous line with closed circles) vs. initial random pool (dashed line with open circles) shows a bimodal distribution of GAS1 solution conformations. F) The selected pdb-files representing the ensemble with $\mathrm{Chi}^{2}=0.84$ fit to the experimental data, showing extended (blue) and more collapsed models (yellow, red, cyan) in the final ensemble; the N-terminal domain (in grey) was fixed relative to the rest of the protein during the runs. The modelled glycan structure is shown as red "stick" presentation on the N-terminal domain.

RET $[31,32])$. However on the cell surface the affinity of GAS1 to RET is also likely to be higher as the diffusion is restricted to two-dimensions.

Another possibility is that in some cellular contexts GAS1 would be highly expressed on cell surface, which might boost the binding to RET locally. The exact mechanism of GAS1 on RET signalling remains elusive, but it seems clear that GAS1 has an effect of RET signalling, probably by inhibiting growth-factor dependent signalling $[4,8]$.

Based on the conservation of protein surface features, as mapped on to the GAS1 models, we suggest that the $\mathrm{N}$-terminal domain region defined by $\alpha$-helices $3-5$ might contain a functional binding site (Figure 4), whereas other possible interaction surfaces remain less clear, e.g. the very short RGD-peptide motif found in mammalian sequences could be functional, or exist by chance, and so far no biochemical evidence for the function exists.

GAS1 has also been reported to alter SHH-signalling through patched-1 [28,33], indicating that GAS1 has multiple functions. Related to this Pineda-Alvarez et al. [34] and Ribeiro et al. [35] reported missense mutations of GAS1 in holoprosencephaly (HPE) patients.In particular Thr200Arg mutation in the second domain of GAS1 Pineda-Alvarez et al. [34] was observed to result 


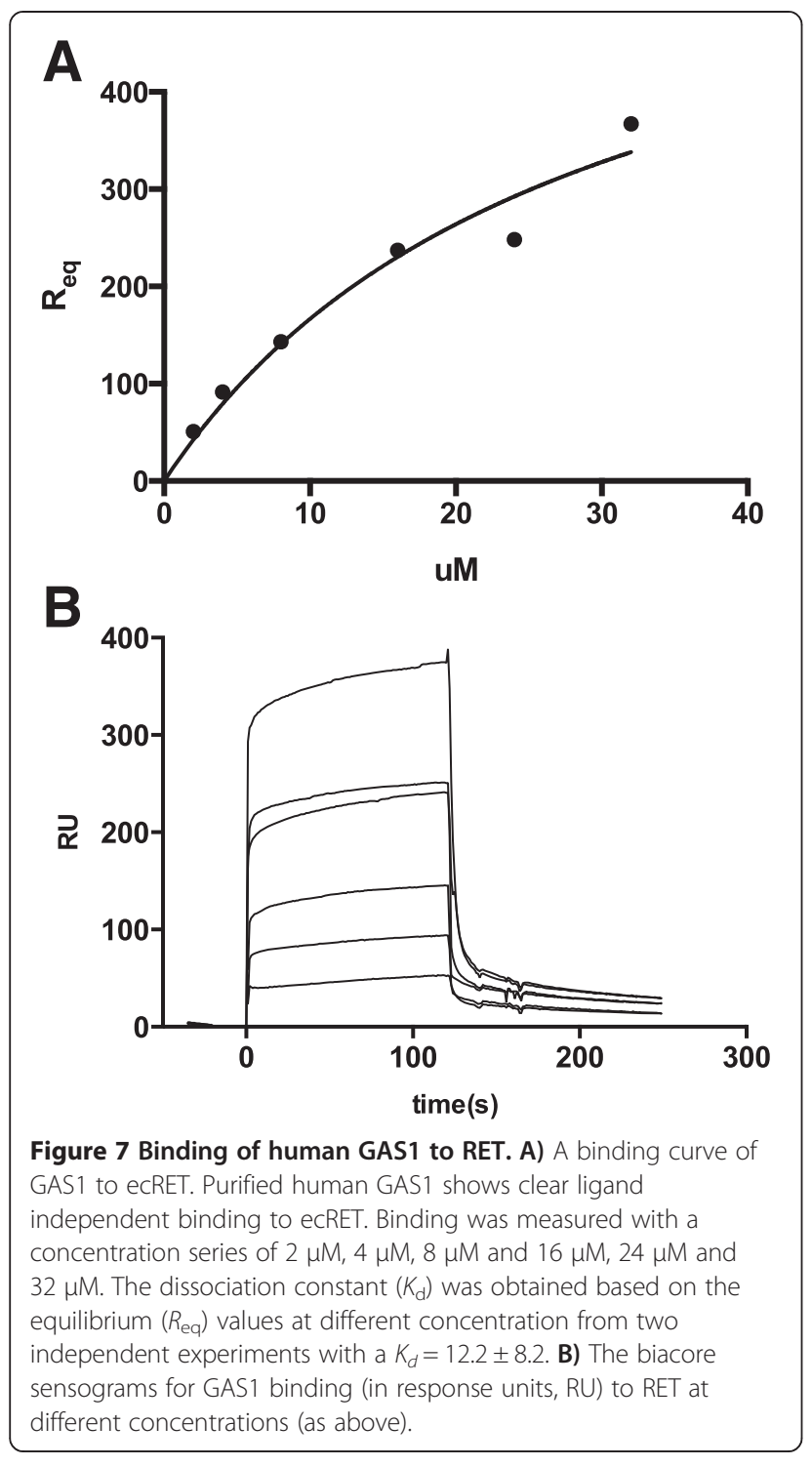

in almost complete loss of binding affinity for $\mathrm{SHH}$, hence this domain could also be important for binding to SHH. Also Asn220Lys caused 20\% reduction in binding according to Pineda-Alvarez et al. [34] and Ala246Ser patient mutations are located in the same domain, while the mutations are some what scattered around the domain and do not cluster together on the surface.

\section{Conclusions}

Our structural data reveal that GAS1 is a flexible twodomain molecule, the flexibility perhaps reflecting its multifunctional properties. The structural arrangement of the domains is clearly different form the compact GFR $\alpha$ structures, suggesting that it has different functional roles. In particular, neither the putative heparan sulphate proteoglycan/RET binding site [22] the known growth factor binding site are conserved in GAS1.
Thus, GAS1 must act on RET in a different way, and together with previous analysis our binding data supports the ligand-independent RET binding by GAS1, while sequence conservation analysis hints at possible sites of functional importance.

\section{Methods}

\section{Ethics statement}

All results of this research were based proteins expressed in cultured Tricoplusia Ni or Spodoptera frugiperda cells lines. Neither human (human subjects, human material or human data) nor animals (vertebrates or any regulated invertebrates) were used in this experimental research.

\section{Plasmids, reagents and cell lines}

Human GAS cDNA1 in a pCR3.1 plasmid was obtained as kind gift from Prof. Mart Saarma, and the pFastBac (Invitrogen) derivative vector pK509.3 from Prof. Kari Keinänen [36]. Oligonucleotides were purchased from Sigma and Phusion polymerase and PCR reagents were from Finnzymes Inc., E.coli DH10Bac-cells, Tricoplusia $\mathrm{Ni}$ and Spodoptera Frugiperda insect cells were from Invitrogen. Serum Free insect cell culture media was purchased from HyClone, gentamycin from Dushefa. Baculovirus production was done according to Bac-to-Bac manual (Invitrogen). SDS-PAGE gels were bought from Bio-Rad. The anti-FLAG monoclonal M1 mouse antibody was from Sigma, the anti-mouse antibody from Santa Cruz biotechnology, $5 \mathrm{ml}$ HisTrap crude Ni-NTA column, size exclusion column Superdex 10/300, and Thrombin protease, $3 \mathrm{M}$ HyBond western-blot membrane, and the ECL reagent were all from GE Healthcare.

\section{PCR and cloning}

Human GAS1 cDNA in pCR3.1 plasmid was used as a template for PCR. The region encoding amino acids 39317 was amplified, thus omitting the part encoding the native secretion signal at the $\mathrm{N}$-terminus and the predicted GPI-anchor in the C-terminus. The PCR product was subcloned between Not1-Hind III restriction sites to baculovirus pFastBac-derivative vector pK509.3, which has the honey bee mellitin secretion signal and a Flagtag sequence upstream of the cloning site.

The forward PCR primer was designed to add additional amino acids at the N-terminus for a $\mathrm{His}_{6}$-tag and a Thrombin protease cleavage site (LRPHHHHHHLVPRGS).

The PCR primer sequences used for cloning were: $5^{\prime}$ ACTTAACTGCGGCCGCATCATCACCATCACCATC TTGTTCCTCGTGGTTCTGCGCACGGCCGCCGCCT CATC-3' (forward) and 5'-AGATCTTAAGCTTACCT GCGCCCAGGCCCATAG-3' (reverse). The template was PCR amplified with 5\% DMSO to optimize it for a high GC-rich template (here, $81.2 \%$ ). PCR cycling 
conditions were as recommended by manufacturer (Finnzymes Inc). Cleaved and agarose gel purified vector and insert were ligated using T4 ligase (New England Biolabs).

\section{Virus propagation and Western-blots}

The GAS1 construct was transformed to DH10Bac-cells to transpose it as a part of baculovirus shuttle-vector. The resulting DNA was isolated as described in the Bac-to-Bac manual (Invitrogen). Baculoviruses were multiplied by transfecting Sf9 cells on Cellstar (GreinerBio-one) six-well plate at $70 \%$ confluency according to the manufacturer's instructions (Mirus. USA). In short, $200 \mu \mathrm{l}$ of serum free HyQ-SFX medium, lacking antibiotics, were placed in microcentrifuge tubes with 6 microliters of Transit reagent (Mirus), and incubated 20 minutes at room temperature. Two micrograms of bacmid DNA was added to the reactions and incubation was continued for another 20 minutes. Cells were washed with phosphate buffered saline (PBS) $\mathrm{pH}$ 7.4, and the medium changed to fresh HyQ-SFX. The transfection mixture was then added to the cells drop-wise. Cells were incubated at $+27^{\circ} \mathrm{C}$ for five hours, after which the medium was changed to serum free SFX medium supplemented with $50 \mu \mathrm{g} / \mathrm{ml}$ Gentamycin. Cells were incubated for five days. The virus production efficacy was estimated by comparing the wells with non-infected control wells; properly infected cells stopped dividing, grew in size, and finally lysed. Virus was passaged typically by infecting $70-90 \%$ confluent plates. Passage one was done by adding $2 \mathrm{ml}$ of virus from transfected cells to $70 \%$ confluent plate, in a total culture volume of $5 \mathrm{ml}$. For passages two and three, $90 \%$ confluent plates were made by infecting cells with three to four millilitres of virus from the previous passage in a total volume of $25 \mathrm{ml}$. Virus propagation was estimated by visual analysis, as described, and by detecting the presence of the flagtagged GAS1 protein by western blot. Virus propagation was typically continued to at least passage four, in order to get sufficient amount of virus to infect the culture used for protein production.

\section{Protein production and purification}

The GAS1 protein was produced by infecting $200 \mathrm{ml}$ of Tn5 cells, typically at $2 \times 10^{6}$ cell density, with $5 \mathrm{ml}$ of high titer virus, typically from passage three or four. $72 \mathrm{~h}$ post infection the cells were harvested by centrifugation and the supernatant was collected.

The secreted GAS1 protein was purified from the supernatant by Ni-affinity chromatography. The column was equilibrated with binding buffer containing $20 \mathrm{mM}$ sodium phosphate $\mathrm{pH}$ 7.4, $150 \mathrm{mM}$ sodium chloride and $5 \mathrm{mM}$ imidazole, and the protein was eluted with linear 5-500 mM imidazole gradient with the binding buffer.
GAS1 protein was detected by SDS-PAGE and identity confirmed by a FLAG-tag Western blot; based on this $1 \mathrm{ml}$ fractions from the peak area were collected (Figure 1).

GAS1 protein containing fractions were detected from the major peak. These pooled and concentrated with a $30 \mathrm{kDa}$ cut-off Amicon spin concentrator (Millipore) for $4000 \mathrm{rpm}$ at $+4^{\circ} \mathrm{C}$, typically up to $500 \mu \mathrm{l}$ volume. The buffer was exchanged, to phosphate buffered saline (PBS), $\mathrm{pH} 7.4$, by diluting to $15 \mathrm{ml}$ and repeating the centrifugation step as described.

After buffer exchange, the tags were cleaved off with Thrombin protease at a ratio of ten units per milligram of protein, the cleaved protein was concentrated to a $350 \mathrm{ul}$ final volume, and further purified using size exclusion chromatography with Superdex 10/300 GL column in a buffer containing Tris-buffered saline (TBS) $\mathrm{pH}$ 7.4, (25 mM Tris $\mathrm{pH} 7.4 ; 150 \mathrm{mM} \mathrm{NaCl} ; 2 \mathrm{mM}$ $\mathrm{KCl}, \mathrm{pH}$ adjusted with $\mathrm{HCl}$ ), supplemented with $250 \mathrm{mM}$ $\mathrm{NaCl}$ at a $0.5 \mathrm{ml} / \mathrm{min}$ flow rate. Fractions of $2 \mathrm{ml}$ were collected and analyzed by SDS-PAGE. The fractions containing correct, approximately $35 \mathrm{kDa}$ protein were pooled and concentrated as previously described.

\section{Surface plasmon resonance assay}

Surface plasmon resonance (Biacore ${ }^{\mathrm{T \omega}}$, GE Healthcare) was used to determine the binding affinity of GAS1 protein to the ectodomain of RET protein (ecRET; R\&D Systems, catalog no. 1168-CR-050/CF).

For this purpose ecRET was coupled to a CM5 chip (GE Healthcare) by amide coupling. The chip was ctivated according to manufacturers instructions with 1ethyl-3-(3-dimethylaminopropyl carbodiimine (EDC)- Nhydroxysuccimide-(NHS) solution (Amine coupling kit, GE Healthcare). The ecRET at $0.25 \mathrm{mg} / \mathrm{ml}$ in PBS was diluted 1:10 to $10 \mathrm{mM} \mathrm{Na}$-acetate,pH 5.0 and coupled to the chip at $4000 \mathrm{RU}$ level.

After ecRET was coupled to the chip, the remaining free activated carboxyl groups on the surface were inactivated with $1 \mathrm{M}$ ethanolamine (GE Healthtcare). The buffer used for binding experiment was $10 \mathrm{mM}$ Hepes pH 7.4, $150 \mathrm{mM} \mathrm{NaCl}$ (HBS) supplemented with $1 \mathrm{mM}$ $\mathrm{CaCl}_{2}, 0.01 \%$ Triton X-100. First flow channel from the chip was used as a blank control channel showing the possible non-specific binding to a non-coated surface. A GAS1 sample concentration series from $2 \mu \mathrm{M}$ to $32 \mu \mathrm{M}$ was injected at $20 \mathrm{ul} / \mathrm{min}$ for 2 minutes, and after each experiment the chip surface was regenerated with $1 \mathrm{M}$ $\mathrm{MgCl}_{2}$ with two $10 \mu \mathrm{l}$ injections to release the bound GAS1 from RET. The dissociation constant for GAS1 to RET binding was calculated from binding curve calculated fitted from the equilibrium response $\left(R_{\text {eq }}\right)$ values for binding at each concentration (Figure 7). 


\section{Small-angle X-ray scattering studies and multi-angle laser light scattering}

The GAS1 protein $a b$ initio solution structure was obtained with $0.8 \mathrm{mg} / \mathrm{ml}$ protein in $50 \mathrm{mM}$ Tris $\mathrm{pH} 7.5$, $50 \mathrm{mM} \mathrm{NaCl}$ buffer. Small-Angle-X-Ray scattering data collection (ESFR, France) was performed with $1 \mathrm{~s}$ exposure time per image, and 10 repeats per sample, and these averaged and subtracted from similarly averaged buffer baseline. The measured data was analysed using PRIMUS [37] software and the $a b$ initio modelling of the protein was done by DAMMIF/DAMAVER software [38]. The model of the protein with flexible linkers was obtained by using rigid body homology modelling against collected data. Original homology modelling of the domains to GFR $\alpha 1$ was done with Raptor-X server and rigid body modelling of the two-domain structure and modelling of flexible linkers was done with CORAL and BUNCH within the ATSAS software package [39]. Ensemble modelling of SAXS data was done using EOM $2.0[38,40]$ via the ATSAS-online server (http://www. embl-hamburg.de/biosaxs/atsas-online/).

\section{Multi-angle laser light scattering}

SEC-MALLS measurements were run at $0.5 \mathrm{ml} / \mathrm{min}$ over an S-200 Superdex 10/300 column (GE Healtcare) in $20 \mathrm{mM}$ TRIS pH 7.4, $150 \mathrm{mM} \mathrm{NaCl}$ with a Schimadzu HPLC system and MiniDAWN TREOS light scattering detector and Optilab rEX refractive index detector (Wyatt Technology Corporation). Data was analysed with ASTRA 6 software (Wyatt Technology Corporation).

\section{Circular Dichroism and thermal stability}

Circular Dichoism (CD) spectrum at $190-260 \mathrm{~nm}$ was collected on a JASCO J-720 instrument. For this experiment the protein was dialyzed against $20 \mathrm{mM} \mathrm{Na}$ phosphate $\mathrm{pH} 7.4,50 \mathrm{mM} \mathrm{NaCl}$. The GAS1 sample was diluted to $6.5 \mu \mathrm{M}$ concentration in the same buffer. Measurement was done with a capped $350 \mu \mathrm{l} 1 \mathrm{~mm}$ light path quartz cuvette (Hellma-Analytics). Data for thermal denatural analysis was collected at $222 \mathrm{~mm}$ wavelength from 20 to $90^{\circ} \mathrm{C}$, with one degree steps and 30 second incubation at each temperature.

\begin{abstract}
Abbreviations
GAS1: Growth arrest specific-1; SAXS: Small-angle X-ray scattering; CD: Circular dichroism; RET: Rearranged during transformation; SEC-MALLS: Size exclusion chromatography and multi-angle light scattering; GFRa: Glial cell-derived neurotrophic factor receptor alpha; GFL: Glial cell-derived neurotrophic factor family ligand; MALDI-TOF: Matrix Assisted Laser Desorption Ionization - Time of Flight; PBS: Phosphate buffer saline; TBS: Tris-buffered saline; SHH: Sonic Hedgehog; GDNF: Glial cell line-derived neurotrophic factor; NCAM: Neural cell adhesion molecule; HBGAM: Heparin-binding growth-associated molecule.
\end{abstract}

\section{Competing interests}

The authors declare that they have no competing interests.

\section{Authors' contributions}

TK, KR, and AG designed experiments. TK and KR performed experiments. TK, $K R$ and $A G$ wrote the paper. All authors read and approved the final manuscript.

\section{Acknowledgements}

We thank Dr. Jaana Jurvansuu for advice and help in the initial stages of this project and Prof. Mart Saarma and Dr. Jaan-Olle Andressoo for insightful discussions and Prof. Saarma for the human GAS1 cDNA. Biacore assays were done with the help of Thomas Strandin and Maria Aatonen. SAXS data were collected at the ID14-3 beam line at ESRF. The MALDI-TOF measurements were done in the Institute of Biotechnology proteomics unit. TK and KR were funded by Academy of Finland grants 256049 and 251700 (to TK), and AG by the Academy of Finland (12522061), by the $7^{\text {th }}$ European Union Framework (CADMAD), and by the Sigrid Juselius Foundation.

\section{Author details}

${ }^{1}$ Institute of Biotechnology, Structural Biology and Biophysics, University of Helsinki, Helsinki, Finland. ${ }^{2}$ Astbury Centre for Structural Molecular Biology, School of Biomedical Sciences, University of Leeds, Leeds, UK. ${ }^{3}$ Department of Biosciences, Division of Biochemistry, University of Helsinki, Helsinki, Finland.

Received: 24 September 2014 Accepted: 6 February 2015

Published online: 28 February 2015

\section{References}

1. Schneider C, King RM, Philipson L. Genes specifically expressed at growth arrest of mammalian cells. Cell. 1988;54(6):787-93.

2. Stebel M, Vatta P, Ruaro ME, Del Sal G, Parton RG, Schneider C. The growth suppressing gas1 product is a GPI-linked protein. FEBS Lett. 2000;481(2):152-8.

3. Del Sal G, Collavin L, Ruaro ME, Edomi P, Saccone S, Valle GD, et al. Structure, function, and chromosome mapping of the growth-suppressing human homologue of the murine gas1 gene. Proc Natl Acad Sci U S A. 1994;91(5):1848-52.

4. Ruaro ME, Stebel M, Vatta P, Marzinotto S, Schneider C. Analysis of the domain requirement in Gas1 growth suppressing activity. FEBS Lett. 2000;481(2):159-63.

5. Del Sal G, Ruaro ME, Philipson L, Schneider C. The growth arrest-specific gene, gas1, is involved in growth suppression. Cell. 1992;70(4):595-607.

6. Del Sal G, Ruaro EM, Utrera R, Cole CN, Levine AJ, Schneider C. Gas1induced growth suppression requires a transactivation-independent p53 function. Mol Cell Biol. 1995;15(12):7152-60.

7. Derry WB, Bierings $R$, van lersel $M$, Satkunendran $T$, Reinke $V$, Rothman JH. Regulation of developmental rate and germ cell proliferation in Caenorhabditis elegans by the p53 gene network. Cell Death Differ. 2007;14(4):662-70.

8. Cabrera JR, Sanchez-Pulido L, Rojas AM, Valencia A, Manes S, Naranjo JR, et al. Gas1 is related to the glial cell-derived neurotrophic factor family receptors alpha and regulates Ret signaling. J Biol Chem. 2006;281(20):14330-9.

9. Lee CS, Fan CM. Embryonic expression patterns of the mouse and chick Gas1 genes. Mech Dev. 2001;101(1-2):293-7.

10. Allen BL, Tenzen T, McMahon AP. The Hedgehog-binding proteins Gas1 and Cdo cooperate to positively regulate Shh signaling during mouse development. Genes Dev. 2007;21(10):1244-57.

11. Martinelli DC, Fan CM. The role of Gas1 in embryonic development and its implications for human disease. Cell Cycle. 2007;6(21):2650-5.

12. Santoro M, Melillo RM, Carlomagno F, Vecchio G, Fusco A. Minireview: RET: normal and abnormal functions. Endocrinology. 2004;145(12):5448-51.

13. Robertson K, Mason I. The GDNF-RET signalling partnership. Trends Genet. 1997:13(1):1-3.

14. Sariola H, Saarma M. Novel functions and signalling pathways for GDNF. J Cell Sci. 2003;116(Pt 19):3855-62.

15. Schueler-Furman O, Glick E, Segovia J, Linial M. Is GAS1 a co-receptor for the GDNF family of ligands? Trends Pharmacol Sci. 2006;27(2):72-7.

16. Airaksinen MS, Titievsky A, Saarma M. GDNF family neurotrophic factor signaling: four masters, one servant? Mol Cell Neurosci. 1999:13(5):313-25.

17. Hatinen $T$, Holm L, Airaksinen MS. Loss of neurturin in frog-comparative genomics study of GDNF family ligand-receptor pairs. Mol Cell Neurosci. 2007;34(2):155-67. 
18. Airaksinen MS, Holm L, Hatinen T. Evolution of the GDNF family ligands and receptors. Brain Behav Evol. 2006;68(3):181-90.

19. Mellstrom B, Cena V, Lamas M, Perales C, Gonzalez C, Naranjo JR. Gas1 is induced during and participates in excitotoxic neuronal death. Mol Cell Neurosci. 2002;19(3):417-29.

20. Lopez-Ramirez MA, Dominguez-Monzon G, Vergara P, Segovia J. Gas1 reduces Ret tyrosine 1062 phosphorylation and alters GDNF-mediated intracellular signaling. Int J Dev Neurosci. 2008;26(5):497-503.

21. Wang X, Baloh RH, Milbrandt J, Garcia KC. Structure of artemin complexed with its receptor GFRalpha3: convergent recognition of glial cell line-derived neurotrophic factors. Structure. 2006;14(6):1083-92.

22. Parkash V, Leppanen VM, Virtanen $H$, Jurvansuu JM, Bespalov MM, Sidorova $Y A$, et al. The structure of the glial cell line-derived neurotrophic factorcoreceptor complex: insights into RET signaling and heparin binding. J Biol Chem. 2008;283(50):35164-72.

23. Mylonas E, Svergun D. Accuracy of molecular mass determination of proteins in solutionby small-angle X-ray scattering. J Appl Cryst. 2007;40(Supplement):245-9.

24. Petoukhov MV, Frank D, Shkumatov AV, Tria A, Kikhney AG, Gajda M, et al. New developments in the ATSAS program package for small-angle scattering data analysis. J Appl Cryst. 2012;45:342-50.

25. Leppanen VM, Bespalov MM, Runeberg-Roos P, Puurand U, Merits A, Saarma $M$, et al. The structure of GFRalpha1 domain 3 reveals new insights into GDNF binding and RET activation. EMBO J. 2004;23(7):1452-62.

26. Agostoni E, Gobessi S, Petrini E, Monte M, Schneider C. Cloning and characterization of the $\mathrm{C}$. elegans gas 1 homolog: phas-1. Biochim Biophys Acta. 2002;1574(1):1-9.

27. Kallberg M, Wang H, Wang S, Peng J, Wang Z, Lu H, et al. Template-based protein structure modeling using the RaptorX web server. Nat Protoc. 2012;7(8):1511-22.

28. Martinelli DC, Fan CM. Gas1 extends the range of Hedgehog action by facilitating its signaling. Genes Dev. 2007;21(10):1231-43.

29. Kallijarvi J, Stratoulias V, Virtanen K, Hietakangas V, Heino TI, Saarma M. Characterization of Drosophila GDNF receptor-like and evidence for its evolutionarily conserved interaction with neural cell adhesion molecule (NCAM)/Fasll. PLoS One. 2012;7(12):e51997.

30. Paratcha G, Ledda F, Ibanez CF. The neural cell adhesion molecule NCAM is an alternative signaling receptor for GDNF family ligands. Cell. 2003;113 (7):867-79.

31. Kjaer S, Ibanez CF. Identification of a surface for binding to the GDNF-GFR alpha 1 complex in the first cadherin-like domain of RET. J Biol Chem. 2003:278(48):47898-904.

32. Trupp M, Arenas E, Fainzilber M, Nilsson AS, Sieber BA, Grigoriou M, et al. Functional receptor for GDNF encoded by the c-ret proto-oncogene. Nature. 1996;381(6585):785-9.

33. Seppala M, Depew MJ, Martinelli DC, Fan CM, Sharpe PT, Cobourne MT. Gas1 is a modifier for holoprosencephaly and genetically interacts with sonic hedgehog. J Clin Invest. 2007:117(6):1575-84.

34. Pineda-Alvarez DE, Roessler E, Hu P, Srivastava K, Solomon BD, Siple CE, et al. Missense substitutions in the GAS1 protein present in holoprosencephaly patients reduce the affinity for its ligand. SHH Hum Genet. 2012:131(2):301-10.

35. Ribeiro LA, Quiezi RG, Nascimento A, Bertolacini CP, Richieri-Costa A. Holoprosencephaly and holoprosencephaly-like phenotype and GAS1 DNA sequence changes: Report of four Brazilian patients. Am J Med Genet A. 2010;152A(7):1688-94.

36. Keinanen $\mathrm{K}$, Jouppila A, Kuusinen A. Characterization of the kainate-binding domain of the glutamate receptor GluR-6 subunit. Biochem J. 1998:330(Pt 3):1461-7.

37. Konarev PV, Volkov W, Sokolova AV, Koch MHJ, Svergun DI. PRIMUS: a Windows PC-based system for small-angle scattering data analysis. J Appl Cryst. 2003;36(5):1277-82

38. Svergun DI. Restoring low resolution structure of biological macromolecules from solution scattering using simulated annealing. Biophys J. 1999;76(6):2879-86.

39. Petoukhov MV, Svergun DI. Applications of small-angle X-ray scattering to biomacromolecular solutions. Int J Biochem Cell Biol. 2013;45(2):429-37.

40. Bernado P, Svergun DI. Analysis of intrinsically disordered proteins by smallangle X-ray scattering. Methods Mol Biol. 2012;896:107-22.

\section{Submit your next manuscript to BioMed Central and take full advantage of:}

- Convenient online submission

- Thorough peer review

- No space constraints or color figure charges

- Immediate publication on acceptance

- Inclusion in PubMed, CAS, Scopus and Google Scholar

- Research which is freely available for redistribution

Submit your manuscript at www.biomedcentral.com/submit 